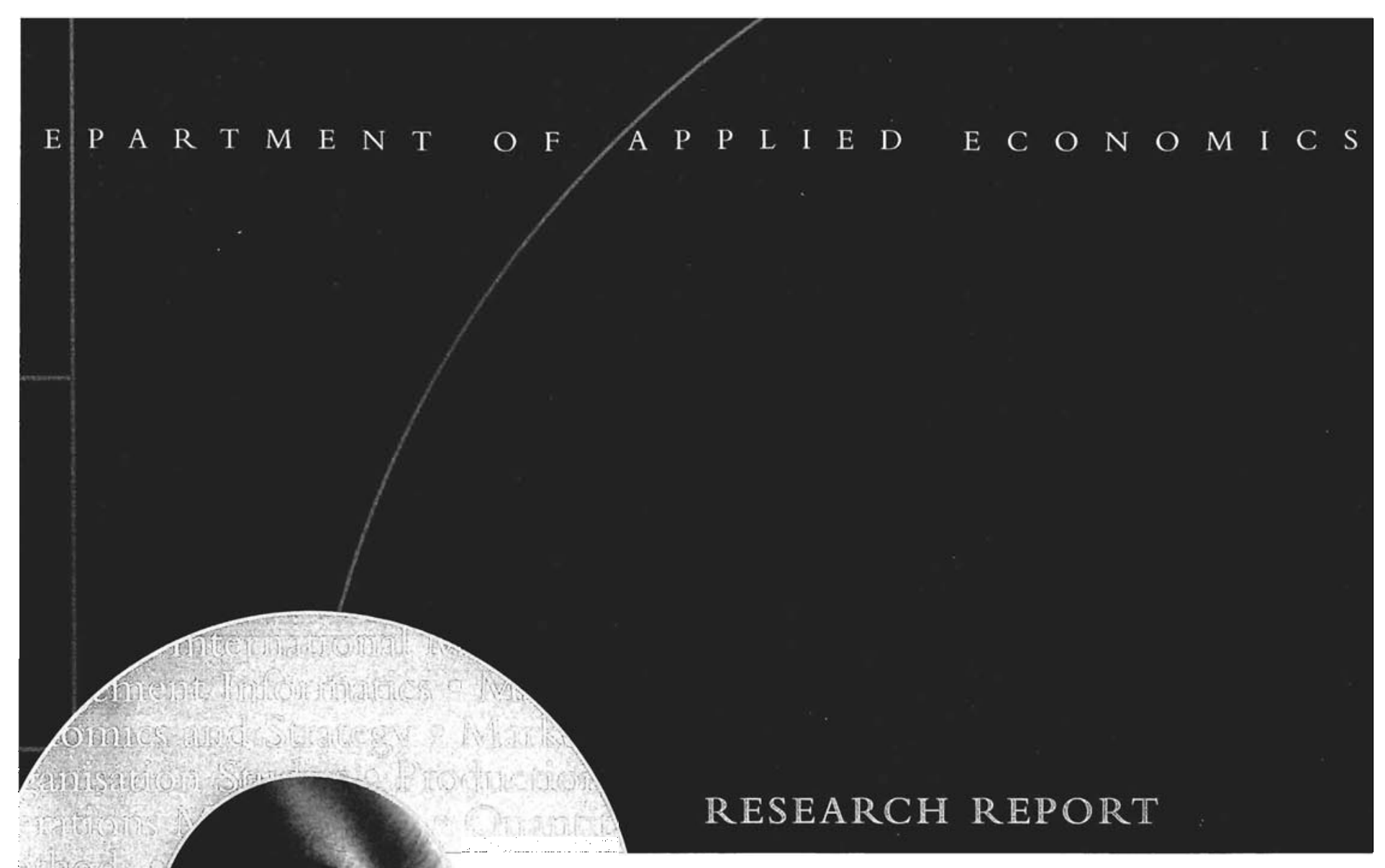

CAN EXTERNALLY ACTIVATED TRAIT CONCEPTS AFFECT PERSON JUDGMENTS AFTER ENCODING?

Davy LeRouge • DiRK SMEESTers $・$ LuK WARLoP

OR 0425 


\title{
Can Externally Activated Trait Concepts Affect \\ Person Judgments After Encoding?
}

\author{
DAVY LEROUGE \\ DIRK SMEESTERS \\ LUK WARLOP*
}

*Davy Lerouge is a doctoral student in Marketing and Luk Warlop is Associate Professor of Marketing, both at the Katholieke Universiteit Leuven, Dept. of Applied Economics, Naamsestraat 69, 3000 Leuven, Belgium. Email : davy.lerouge@econ.kuleuven.ac.be and luk.warlop@econ.kuleuven.ac.be , Phone: + 321632 69 41, Fax: + 32163267 32. Dirk Smeesters is Assitant Professor of Marketing at Tilburg University. Email :

d.smeesters@uvt.nl, Phone : +31 134668252 


\title{
Can Externally Activated Trait Concepts Affect
}

\author{
Person Judgments After Encoding?
}

\author{
Department of Applied Economics \\ Katholieke Universiteit Leuven
}

\begin{abstract}
Current knowledge accessibility research assumes primed trait concepts to have no biasing effects beyond the encoding stage. In a series of studies, we challenge this assumption. We predict that trait concepts still can influence the person judgments of a predictor who previously stored the target person information through selective retrieval of trait congruent information. Our results consistently reveal assimilation effects when participants are primed with traits at judgment. Moreover, we identify two boundary conditions provide further evidence of the underlying selective retrieval process. First, assimilation effects only occur when stored target person instances apply to the externally activated knowledge and, second, when no prior target person impression is formed.
\end{abstract}




\section{Introduction}

The focus of this paper is on the effect of subtle external cues on the judgments an actor makes about another person. In a marketing context these judgments are often predictions of another person's product attitudes or preferences. Such predictive judgments are necessary whenever a consumer acts as an agent for another consumer, or when one is buying a product as a gift for someone else. Very specific also to the marketing context is that the external cues that might influence these judgments are often embedded in the retailing environment at the time of purchase, and that the agent already possesses at least some knowledge on the target person about whom the predictions are made before entering the purchase episode. There is strong evidence that people, when they judge another person, are unlikely to search memory for all information that might be relevant for their judgment. Instead they tend to base their judgment on only the subset of knowledge that is made more readily accessible by the context in which the judgment is made (Tversky and Kahneman 1973, 1974).

Effects of external context on such judgments are amply documented as 'priming effects' in the social cognition research tradition. However, within the social cognition field, the debate on the precise impact of primes encountered at the time of judgment ('post-priming') is far from resolved. We will try to resolve some of the remaining controversies on this matter, thereby laying the groundwork for future consumer research studying the effect of subtle environmental cues, like store atmosphere or product advertisements, on predictions of an other's product attitudes, like when buying a birthday gift.

We introduce the specific questions addressed in this article as following a brief overview of prior social cognition research on knowledge accessibility effects on person impressions. 


\section{Knowledge activation in a nutshell}

Two different streams of research studied the effects of knowledge activation (Stapel, Koomen and van der Pligt 1997). On the one hand, social cognition research investigated the impact of activated knowledge on the subsequent interpretation of ambiguous stimuli. In this kind of research, people were typically primed with personality traits. This priming generally induces the assimilation of a vague or ambiguous target person towards the valence of the primed concept. A frequently cited and often replicated example is a study by Srull and Wyer (1979) (see also Higgins, Rholes and Jones 1977, Wyer and Srull 1989). They used a priming task in which they exposed participants to hostile or kind behavioral descriptions that either activate the "hostility" or the "kindness" construct. Participants were then asked to judge a vague target person, Donald, whose behaviors were close to neutral with respect to kindness. They found that Donald was perceived as being more hostile when primed with hostility and more kind when primed with the kindness concept.

In the social judgment research tradition, on the other hand, the basic assumption has been that all judgments are comparative (Eiser 1990) and that, by consequence, accessible person exemplars are used when making social judgments. The typical finding in this type of research is nicely illustrated in a study by Herr, Sherman and Fazio (1983). They found that when participants were primed with moderate exemplars of animal ferocity or size, assimilation effects appeared when the participants judged a fictitious animal on ferocity or size. No effect was found for a real animal. However, when participants were primed with extreme exemplars, the priming produced contrast effects both for fictitious and real animals. Comparable results were found in Herr's (1986) study that looks at the effects of exemplars, varying in their degree of hostility, on kindness judgments of the vague target person used by Srull and Wyer (1979). The explanation of these findings was that when a target person is vague or ambiguous, the judge is searching for an appropriate identifying category like the moderate exemplar. When the exemplar is too extreme, it falls outside the latitude of acceptance and contrast effects emerge.

Stapel, Koomen and van der Pligt $(1996,1997)$ combined both research streams in their two-stage interpretation/comparison model (see also Stapel and Koomen 2001). 
According to this model, vague and ambiguous behaviors are interpreted and judged with respect to the construct that is most accessible at the time the information is received. This means that during encoding, the activated construct can serve as an interpretation framework, resulting in assimilation effects. Later at the time of judgment, however, accessible information might affect the impression formation as a comparison standard, leading to contrast effects. Applied to the two types of primes, this model predicts that person exemplars can be used both as an interpretation framework when encoding target person information and as a comparison standard at the judgment stage. Trait concepts, lacking comparison relevance, only affect the encoding of vague or ambiguous stimuli.

In this paper, we examine the effect of activated knowledge after the encoding stage. More specifically we propose that the knowledge activated during the judgment of the target person will not only be used as a comparison standard (as found in previous studies) but that it will also affect the kind of target person information that is retrieved. We assume that, in order to make their judgment, we assume that consumers first have to retrieve diagnostic cues. We further expect that this retrieval can also be influenced by the knowledge that is activated at that time. Our view is consistent with Stapel and Koomen (2001, p. 230) who also note:

"Knowledge accessibility may determine which stimuli are given attention, how those stimuli are encoded, the way in which they are stored and retrieved from memory, and how they are evaluated and judged".

Before we take a closer look at the studies that investigated the impact of external cues at the time of judgment, we first discuss how target person information is stored in memory and what types of stored target person information can be distinguished. Both factors can have an important influence on how the activated knowledge at judgment affects the perception of the target person. 


\section{Encoding of the target person information}

Many prior studies have documented how information is encoded in the absence of explicit instructions. A lot of this research was conducted by Uleman and colleagues (see Uleman, Newman and Moskowitz 1996 for a review), who argued that people engage in spontaneous trait inference when they are exposed to the behavior of others. Typically, the evidence for spontaneous trait inference comes from experiments in which people attend to descriptions of others' behavior. These behavioral descriptions are as concrete as possible and clearly imply specific personality traits (e.g. "The librarian carries the old woman's groceries across the street."). Winter and Uleman (1984) for instance found that, although participants were not encouraged to form impressions, the traits subsequently served as effective retrieval cues for these behavioral instances. These spontaneous trait inferences were initially thought to reflect the spontaneous attribution of traits to the people performing the behaviors. The conclusion drawn from these studies has been questioned by others (e.g. Bassili 1989, Claeys 1990), and also Uleman later admitted that their findings not necessarily prove that the inferences refer to the actor. It is also quite possible that the spontaneous inferences refer not to the actor but to the behavior descriptions themselves (Uleman et al. 1993). More recent research suggests that it depends on the circumstances. For instance, the goals and motivation of the perceiver are found to affect the likelihood that trait inferences activate dispositions or actor-trait links instead of mere behavioral descriptions (Uleman and Moskowitz 1994). Participants who had an impression formation goal when reading trait-implying behaviors were found to attribute those traits to the actor, while those having a memorization task activated abstract behavior labels. This view also comports with the person memory literature. This literature indicates that social information tends not to be organized around person categories unless the perceiver is given an instructional set facilitating such organization (e.g. Srull 1983). The fact that people do not spontaneously infer target person traits when they encode the target person's behaviors has important implications for the effect of activated knowledge at judgment stage (see infra). 


\section{Different types of target person information}

The information people possess about another person consists of different behavioral instances, they observed themselves or heard being described by others. Based on the applicability of the activated construct to the target person's behavioral instances, different types of target person information can be distinguished (Higgins and Brendl 1995, Higgins 1996; Stapel and Schwarz 1998). A first type is the unambiguous target person information. This target person consists of behaviors that only apply to one trait construct and that all point towards the same pole of this construct. An example of this is target person information that exclusively contains extremely hostile behavioral instances.

Target person information can also be ambiguous. Ambiguous target person information consists of behavioral instances that all apply to at least two alternative constructs that are equally applicable. An example of such a description is the target person used by Carlston (1980) and described with behaviors that each individually could be interpreted as either kind or dishonest (e.g., "Michael helps a friend complete a takehome exam"). These target persons lack evaluative clarity because the meaning of the behavior itself is ambiguous.

A target person can also be missing evaluative certainty not because the individual behaviors are ambiguous, but because the combination of behaviors has contradictory implications. These target persons are defined as mixed. One type of mixed target persons has some behaviors that imply a construct at one pole while others imply the opposite pole of the same construct. Skowronski, Carlston and Isham (1993) for instance constructed a behavioral description that both included intelligent (e.g., "he is a skilled craftsman") and unintelligent (e.g., "he did not well in school") behaviors. Another possibility is that some behavioral instances strongly imply one construct and others a different but evaluatively opposite construct. Carlston (1980) for instance made use of three behaviors implying kindness (e.g., "When Michael learned that John had failed his exam, he sought John out to console him") and three behaviors implying dishonesty (e.g., "Michael copied an article from the JESP and submitted it as his final research project in his psychology class"). 
Finally, there is also the vague target person whose behaviors are only weakly related to the activated trait construct. The vaguely hostile Donald description of Srull and Wyer (1979) consisted of six behaviors that all scored around the midpoint of a kindness scale (e.g., "a salesman knocked at the door, but Donald refused to let him enter"). Since these behaviors do not contain much information with respect to the activated kindness or hostility trait, this target person also lacks evaluative clarity.

Although the above classification clearly shows the diversity of used target person descriptions, research into knowledge activation has paid relatively little attention to its effect on social judgments (Higgins and Brendl 1995). Stapel and Schwarz (1998), for instance, found that although trait primes led to assimilation effects for both ambiguous and mixed target person descriptions, the underlying mechanism is quite different. Trait priming was found to play an interpretative role in the disambiguation of the information in ambiguous descriptions, while it elicited the selective processing of some, rather than other, features of the mixed target person information.

\section{Knowledge activation at the judgment stage}

According to the interpretation/comparison model the only knowledge activation effects that can appear after encoding are contrast effects. More specifically Stapel, Koomen and van der Pligt (1997) argued that only activated extreme exemplars are likely to result in a contrast effect because they are more distinct and have more comparison relevance than trait concepts. They supported the argument by first supplying the participants with a vague Donald description and subsequently priming them with either trait concepts ("nice, gentle and friendly" vs. "mean, violent and unfriendly") or extreme person exemplars (“Aladdin, Ghandi and Mandela" vs. "Dracula, Stalin and Hitler"). Only the extreme exemplar post-primes affected the subsequent kindness ratings. Post-priming with trait concepts did not influence the kindness perception of Donald. The same pattern was also found with respect to the participants' kindness ratings of a good friend. These findings were consistent with an earlier study of Srull and Wyer (1980, experiment 3) who post-primed with hostility trait concepts and manipulated the number of primes (15 vs. 35 ), the delay (no delay vs. 24 hours) and type of delay (between stimulus presentation 
and priming vs. between priming and judgment). In none of these conditions the postprimes had any effect on the ratings of the target person.

At this point we might be tempted to conclude that the activation of trait concepts does not have any effect at the judgment stage. In the present study, we want to challenge this. We predict that activated trait concepts can have an effect on target person judgments even when the target person information was previously stored in memory. As discussed above, when no encoding goal is specified, this stored information very likely consists of behavioral instances that are spontaneously linked to their applicable trait (Srull 1983, Uleman and Moskowitz 1994). Since people are generally not expected to have made personality inferences about the focus trait at encoding, they will have to rely on the stored behavioral information at the moment when they are asked to judge the target person on the focus trait. When a trait concept is activated at this judgment stage, it is expected to affect the judgment because prime-congruent features will become more accessible. The studies on spontaneous trait inferences, for instance, found that the traits corresponding to the behaviors serve as effective retrieval cues for these behaviors (e.g., Winter and Uleman 1984). The higher accessibility of behaviors congruent with the activated trait could be interpreted as a cue for the frequency and probability of these behaviors (Tversky and Kahneman 1973) and ultimately result in an assimilation effect at the prediction stage.

Why did previous post-priming studies find no effect of the activated trait concepts? One likely reason is that both the study of Srull and Wyer (1980) and Stapel et al. (1997) made use of a vague target person description with behaviors that, by definition, do not strongly apply to the activated trait concept. For this reason, we assume that the trait concept could not serve as an effective retrieval cue. Another possible reason is that in both studies the participants were asked to form an impression of the target person at the encoding stage. Since it is found that people with an impression formation goal attributed the inferred trait directly to the target person (Uleman and Moskowitz 1994), the participants very likely recalled and used this inference at the judgment stage instead of basing their judgment on the behavioral instances (Carlston 1980, Ostrom et al. 1980, Srull and Wyer 1980). In the present studies, we will experimentally test both explanations. 


\section{Study 1}

The aim of this study was twofold. First, and in contrast with the interpretation/comparison model of Stapel et al. (1997), we wanted to find out if we could obtain an assimilation effect when a trait concept was activated at judgment stage. Second, we examined to what extent this assimilation effect depended on the type of target person information. We expected that the primed trait concept would increase the accessibility of behavioral instances that were congruent with this trait. Therefore, we expected that if people had encoded mixed target person information (kind and unkind behaviors), an assimilation effect towards the primed trait valence would occur. More specifically, we expected that participants that were post-primed with kindness related traits would judge the target person as kinder. For participants post-primed with traits related to hostility, the perception of the target person would be less kind. Next, we also expected that participants provided with a vague target person would not be affected by the activated trait concepts. Since the behaviors of the vague target person did not apply to the primed trait, we expected that the participants that are post-primed with kindness traits would judge the target person equally kind as those that were primed with hostility traits. In short, we expected an assimilation effect of the post-primes after people read the mixed target person description and no effect of the post-primes when people had encoded the information of a vague target person.

\section{Pretest}

Selection of behavioral descriptions

We compiled a set of 15 different situations (e.g., "D. is talking with a group of friends, when they see a girl hurry, stumble and fall. D. makes his friends aware of this."). Each situation was followed by a vague (e.g., "They see that the girl hurries back on her feet and they continue their conversation."), a kind (e.g., "D. hurries to the girl, helps her back on her feet and asks if she has hurt herself."), or an unkind ("And they all start laughing. Ashamed, the girl hurries up and leaves.") behavioral variant. In total 45 
behavioral descriptions were constructed. These behaviors were divided over three questionnaires each containing one of the variants for each situation. Each questionnaire consisted of five kind, five unkind and five vague individual behaviors.

Seventy pre-test respondents were randomly given one of the three questionnaires in which we asked them to rate the 15 behavioral instances along a scale from 1 ("not at all kind") to 7 ("extremely kind"). From this pool, we selected six situations for which we had a vague behavioral variant and either a kind or an unkind variant. This selection was based on two criteria. First, the kindness rating of the vague variant did not differ significantly from four, the neutral point on the scale, and second, the rating was significantly higher (lower) than its unkind (kind) variant. This reduced our initial pool to a set of six vague $(M=3.84)$, three kind $(M=6.20)$ and three unkind $(\mathrm{M}=1.81)$ instances. The six selected behaviors that were found to be vague with respect to kindness formed the description of our vague target person. The three kind and unkind behaviors formed the description of our mixed target person.

\section{Test of target person descriptions}

To test whether the overall kindness of the vague and mixed target person descriptions was perceived as identical, 37 respondents were asked to rate the target person description, featuring a man named Diederik with respect to kindness. They received a two-page bundle. On the first page, after Diederik was briefly introduced as a student, we asked them to read several episodes taken from his life. Half of the participants then read the vague target person description, which was the following ${ }^{1}$ :

Diederik strolls down a neighborhood that is unfamiliar to him. Along his way he sees a tourist with a city map, who is clearly searching for something. Because Diederik himself hardly knows his way around in this neighborhood, he passes the tourist.

Diederik meets an acquaintance at a vending machine. The acquaintance tells him that he planned to buy a soft drink but unfortunately he ran out of coins. At that moment, Diederik notices that he has no cash either.

Diederik is talking with a group of friends, when they see a girl hurry, stumble and fall. Diederik makes his friends aware of this, but in the meantime the girl hurries back on her feet. So they continue their conversation.

\footnotetext{
${ }^{1}$ These are translations. The descriptions used in our studies were in Dutch. Minor deviations due to translation are possible.
} 
A friend of Diederik is preparing for a very difficult exam. Diederik, an expert in that subject, knows that his friend has a lot of problems with this course. However, Diederik can't help his friend because, at the same time, he has to prepare for another exam himself.

Diederik runs into a friend in the street and they start talking. As they are about to say goodbye, Diederik asks him about his plans for the evening. His friend tells him that he would really love to go to a sports event but he has no transportation to the sports center that is situated further down town. Diederik tells him that it is a pity his friend has to miss out on the game and they part.

On Friday evening, just after Diederik finished his final exam, his friends ring at the door and ask him to go out and party. Although Diederik's girlfriend still has a difficult exam the next day, he decides to join them for a while. He promises to be back shortly.

The other half of the participants were asked to read this mixed target person description:

Diederik walks around in a neighborhood that is quite familiar to him. Along his way he sees a tourist with a city map clearly searching for something. Diederik walks up to the man and together they try to find the right direction.

Diederik meets an acquaintance at a vending machine. The acquaintance tells him that he planned to buy a soft drink but unfortunately he ran out of coins. Diederik immediately proposes to lend him some money.

Diederik is talking with a group of friends, when they see a girl hurry, stumble and fall. Diederik makes his friends aware of what he has just seen and they start laughing. Ashamed, the girl hurries up and leaves.

A friend of Diederik is preparing for a very difficult exam. Diederik, an expert in that subject, knows that his friend has a lot of problems with this course. However, he refuses to help him prepare this exam. He doesn't want his friend to get a better grade thanks to him.

Diederik runs into a friend in the street and they start talking. As they are about to say goodbye, Diederik asks him about his plans for the evening. His friend tells him that he would really love to go to a sports event but he has no transportation to the sports center that is situated further down town. Diederik, who owns a car, immediately proposes to drive his friend to the sports event. This way, his friend will still be able to follow the game.

On Friday evening, just after Diederik finished his final exam, his friends ring at the door and ask him to go out and party. Although Diederik's girlfriend still has a difficult exam the next they, and she could use his support, Diederik decides to join them. That evening he has the time of his life and it is early in the morning when he returns home, drunk.

Two alternative versions of the questionnaires, changing the sequence of the individual behaviors, were constructed. On the next page, the respondents were asked to rate Diederik on a seven-point kindness scale ( $1=$ not at all kind, $7=$ very kind). They were not allowed to return to the previous page. Irrespective of the version, respondents 
perceived the mixed target person $(\mathrm{M}=3.85)$ as not different compared to the vague one $(\mathrm{M}=3.86)(\mathrm{F}(1,25)<.01, \mathrm{p}>.98)$ on the kindness dimension. Also neither the ratings of the mixed nor the vague target person differed significantly from the midpoint of the scale.

\section{Study 1a}

\section{Method}

\section{Participants and design}

The participants were 82 students at Katholieke Hogeschool Leuven, participating in partial fulfillment of course requirements. They were randomly assigned to the conditions of a 2 (target person description: vague vs. mixed) x 2 (prime valence: kind vs. unkind) between subjects design. The dependent variables were the participants' kindness judgment and overall impression of the target person Diederik.

\section{Procedure and materials}

The study was part of a general testing session in which participants were asked to complete several tasks. On arrival at the laboratory, participants were placed in individual cubicles. The participants were told that they would participate in a number of unrelated studies. They were requested to perform a sequence of four tasks: (a) a reading task; (b) a filler task; (c) the task involving the priming procedure and (d) the judgment task. After the participants completed these tasks, they were requested to fill out a post-experimental questionnaire. This questionnaire probed for their awareness of the priming manipulation or suspicions about any relatedness among tasks (similar to Higgins and Brendl 1995). Finally, we thanked them for their participation. When the entire study was finished, we debriefed them. Five participants were not included in the analyses. Four participants suspected a connection between the priming and judgment task and one participant failed to correctly execute the priming task. 


\section{$\underline{\text { Reading and filler task }}$}

In this first task, the participants are asked to carefully read the target person description presented on the first page. Half of the participants read the vague target person description while the other half read the mixed target person description. When turning to the next page, they were asked to count down from 60 to zero in steps of three. After this small counting exercise, the participants handed in their package and proceeded to an unrelated filler task. Both the counting exercise and filler task were intended merely to mask the manipulation of this experiment.

\section{Priming manipulation}

Next, the participants were asked to fill out a scrambled sentence task (see Srull and Wyer 1979). The task was introduced as a "language skill" test and consisted of 14 scrambled five-word sets. The participants' assignment was to organize the word sets into meaningful, grammatically correct sentences using four out of the five words. For each word set only one solution was possible ${ }^{2}$. Prime words were embedded in eight of the 14 word groups. For half of the participants these prime words were related to kindness: sweet, gentle, kind, pleasant, good, polite, friendly and helpful. In the unkind valence condition these traits were: mean, hostile, disagreeable, coarse, bad, impolite, unfriendly, and rude ${ }^{3}$.

\section{$\underline{\text { Judgment task }}$}

During this final task, the participants are asked to judge Diederik on 7-pointscales with respect to kindness ( $1=$ not at all friendly, $7=$ very friendly $)$. We also asked their overall impression of the target person $(1=$ extremely negative, $7=$ extremely positive).

\footnotetext{
${ }^{2}$ One example of such a word set is: "bush, big, a, garden, planting". The correct answer is: "planting a big bush".

${ }^{3}$ In our studies, the prime words were presented in Dutch. The Dutch prime words related to kindness were: "lief", "zachtaardig", "sympathiek", "aardig", "goed", "beleefd", "vriendelijk" and "hulpvaardig". The unkind traits were "gemeen", "kwaadaardig", "onsympathiek", "grof", "slecht”, "onbeleefd", "onvriendelijk" en "onbeschoft".
} 


\section{Results and discussion}

We performed a 2 (target person description: mixed vs. vague) x 2 (prime valence: kind vs. unkind) between-subjects ANOVA on the kindness judgment. We obtained a main effect of target person description. Rated kindness is higher for the mixed target person $(M=4.22)$ than for the vague one $(M=3.25)(F(1,83)=12.61, p<.001)$. More interestingly, we found a significant interaction between target person description and prime valence $(F(1,73)=7.61, p<.03)$. The interaction means are shown in figure 2.1.

\section{FIGURE 1}

MEAN KINDNESS JUDGMENT AS A FUNCTION OF TARGET PERSON DESCRIPTION AND PRIME VALENCE (STUDY 1a)

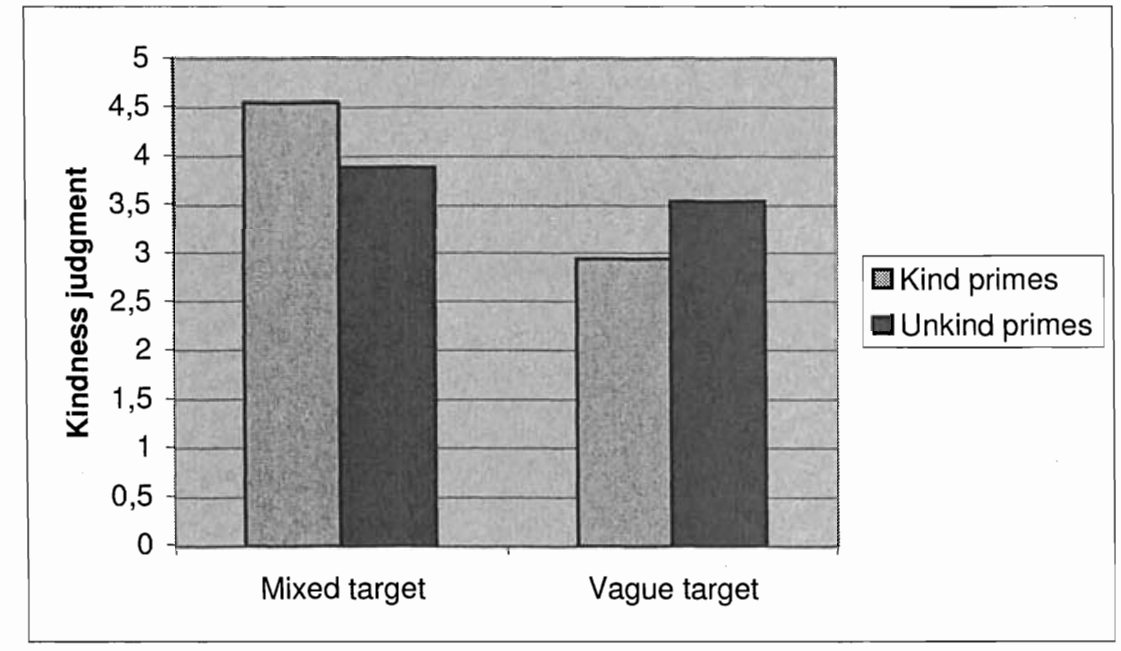

As predicted, the data revealed a difference in the mixed target person condition. When participants were post-primed with the kindness concept $(M=4.57)$ they judged the target person as kinder than when they were post-primed with the hostility concept $(M=$ 3.89). However, this difference was only marginally significant $(F(1,73)=3.01, p<.09)$. The difference between kind and unkind primes was not significant in the vague target person condition $(M=2.95$ vs. $M=3.53 ; F(1,73)=2.07, p>.15)$. As expected, in the vague target person condition no assimilation effect was observed.

The same ANOVA was also computed with the general impression rating as dependent measure. One participant who failed to complete this item was excluded from 
the analysis. We obtained only a main effect of target person type. The mixed target person $(M=3.78)$ was perceived as more positive than the vague target person $(M=3.26)$ $(F(1,72)=5.01, p<.05)$. No effect of prime valence was found.

The results provided some support for our expectations. When the description of the target person consisted of mixed behaviors, people perceived the target person as kinder when kind traits were activated than when unkind traits were activated. This assimilation effect was only marginally significant, however. When the target person was vague, no assimilation effect of the activated traits was found. The results even leaned towards a contrast effect. The persons who received the kind primes perceived the target person slightly more unkind than those primed with unkind traits.

\section{Study $1 b$}

In this study, we made an attempt to fine-tune the procedure and ran the experiment on a second subject pool in order to find more convincing evidence for our expectations.

\section{Method}

\section{Participants and design}

In total 66 undergraduate students of Tilburg University participated in this study. Their participation was in partial fulfillment of course requirements. The experimental design included the same two between-subjects factors as in study 1a. The kindness judgment and overall impression rating of the target person were again the dependent measures. 
The procedure was similar to the procedure in study 1a, except for some minor adaptations. We changed the trait primes in an attempt to obtain more symmetry in the prime effects. In the above study the data suggest a stronger impact of the kind compared to the unkind trait primes. In the priming task of this study, the primes in the kind condition were: liked, good-hearted, sympathetic, good, polite, helpful, pleasant and warm. The exact opposite of these traits was used in the unkind condition: disliked, evilhearted, unsympathetic, bad, impolite, unhelpful, unpleasant, and cold ${ }^{4}$. The word groups in which we embedded the prime words were identical for both conditions. We also extended the judgment task to 11 personality judgments. Each personality trait had to be rated on a seven-point scale. This was done to make it less obvious for the participants that kindness was the focal trait. To minimize the effect of the other trait ratings on the kindness rating, it was second on the list, after the unrelated intelligence trait. At the end of this list, we asked the participants to give their overall target person impression $(1=$ extremely negative, $7=$ extremely positive).

\section{Results and discussion}

Like in study la we conducted a 2 (target person description: mixed vs. vague) x 2 (prime valence: kind vs. unkind) between-subjects ANOVA on the kindness and the overall impression ratings. With respect to the kindness rating, the results were quite similar to the findings of study $1 \mathrm{a}$. We found a main effect of target person description $(F(1,62)=9.97, p<.01)$. The participants perceived the mixed target person $(M=3.72)$ as kinder than the vague target person $(M=2.94)$. Congruent with study $1 \mathrm{~b}$, this effect was qualified by a significant interaction with prime valence $(F(1,62)=4.65, p<.04)$. The means of this interaction are presented in figure 2.2.

\footnotetext{
${ }^{4}$ The Dutch prime words related to kindness were: "geliefd", "goedaardig", "sympathiek", "goed", "beleefd", "behulpzaam", "aangenaam" and "warm". The unkind traits were "ongeliefd", "kwaadaardig", "onsympathiek", "slecht", “onbeleefd”, “onbehulpzaam”, "onaangenaam" en "koud”.
} 
FIGURE 2

MEAN KINDNESS JUDGMENT AS A FUNCTION OF TARGET PERSON DESCRIPTION AND PRIME VALENCE (STUDY 1b)

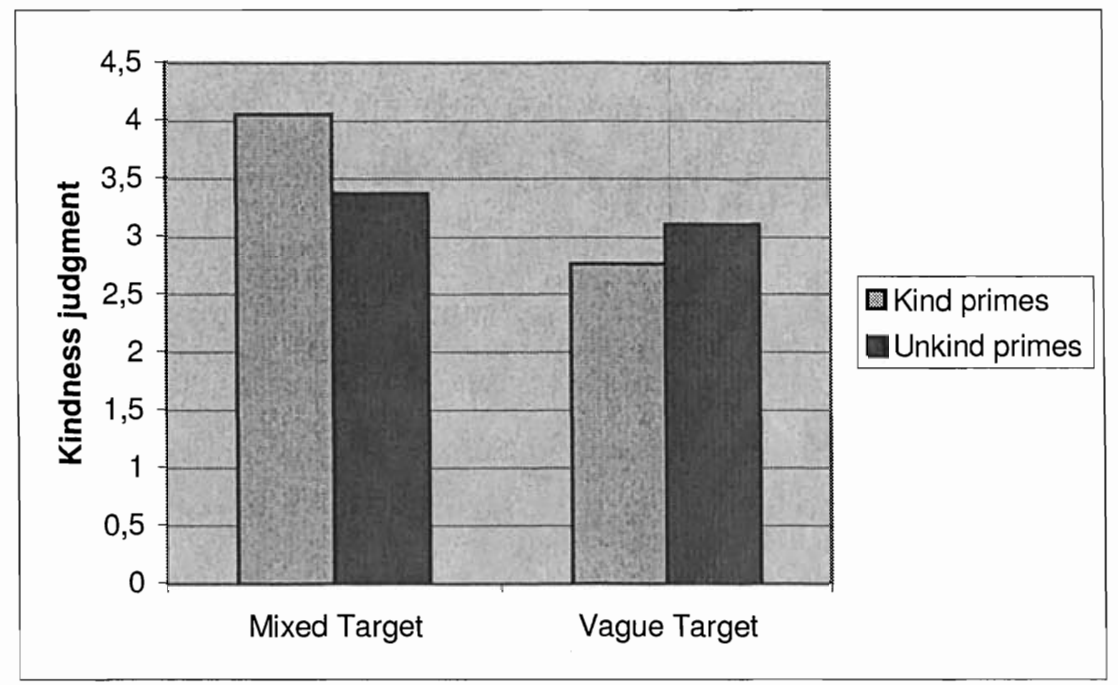

Subsequent analyses revealed, consistent with study 1a, an assimilation effect when the target person description was mixed $(F(1,62)=3.94, p<.06)$. People rated the mixed target person higher on kindness when they were post-primed with kind traits $(M=$ 4.06), compared to unkind traits $(M=3.38)$. When the target person condition was vague, however, no significant difference between the kind and unkind prime conditions appeared $(M=2.76$ vs. $M=3.12)(F(1,62)=1.10, p>.29)$.

This pattern was also found with respect to the overall impressions. As depicted in figure 3 , the post-prime effect interacted significantly with target person description $(F(1$, $61)=6,41, p<.02)$.

More specifically, the mixed target person was judged more positive in the kind ( $M$ $=3.88)$ compared to the unkind prime valence condition $(M=3.06)(F(1,61)=4.98, p<$ $.03)$. With respect to the vague target person, again no significant effect of prime valence is found $(M=2.81$ vs. $M=3.30)(F(1,61)=1.80, p>.18)$. 
FIGURE 3

OVERALL TARGET PERSON JUDGMENT AS A FUNCTION OF TARGET PERSON DESCRIPTION AND PRIME VALENCE ON (STUDY $1 \mathrm{~b}$ )

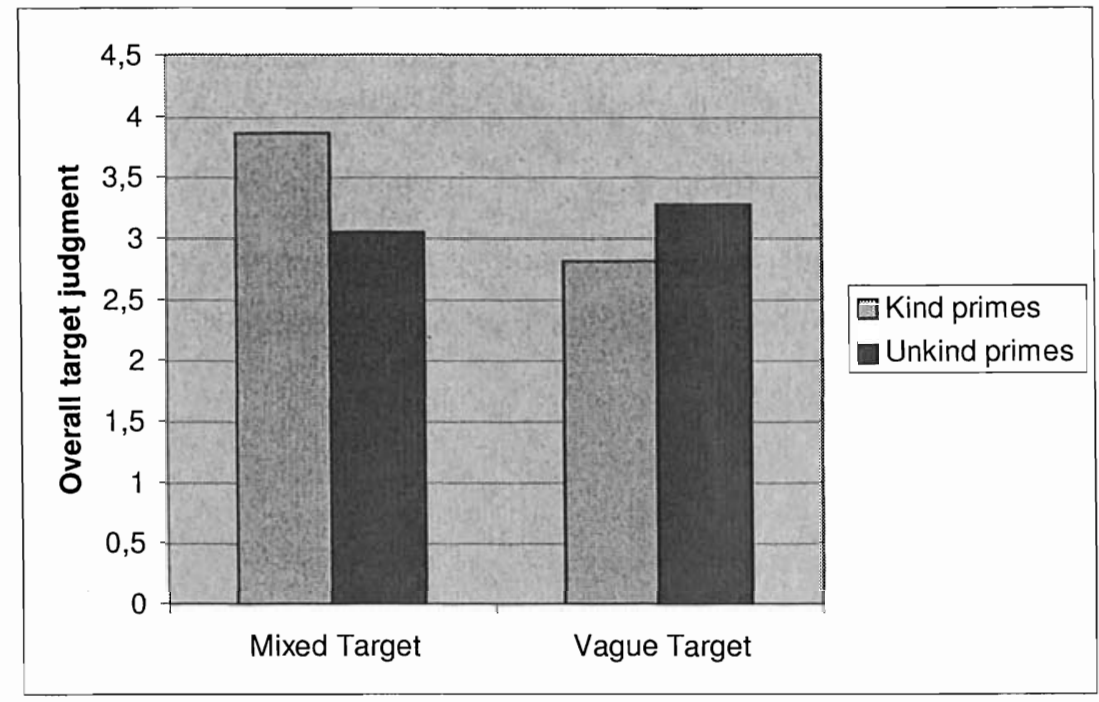

The results of this study confirm our findings in study 1a. When the target person information is mixed, the data reveal the expected assimilation effect of the post-primes. When only vague behaviors of the target person are available, the post-primes do not affect the kindness judgment. Nonetheless, we are still concerned by two unexpected observations. First, we consistently found a significant main effect of target person description. The vague target person is perceived as less kind than the mixed target person. Second, there also seems to be a consistent, although not significant, tendency for a contrast effect in the vague target person condition. Awareness of the priming events is often found to unpredictably influence the effect of target person knowledge on subsequent target person judgments (Higgins 1996). Since post-primes are provided between two target person-related tasks (i.e. reading and judgment task), the present procedure was especially vulnerable to this awareness effect. We tried to remedy this in study 2 . 


\section{Study 2}

Although the results of study 1 were reasonably satisfactory and in line with our expectations, we wanted to filter out all possible confounding effects of prime awareness. We opted for a subliminal priming procedure in study 2. Using this approach, we also tested the robustness of our findings to another priming procedure. Instead of priming participants with word sets implying either kind or unkind behaviors, we used the actual traits as primes in this study.

\section{Method}

\section{Participants and Design}

Sixty-one students of Tilburg University took part in this experiment to fulfill course requirements. The experimental design included two between-subjects factors: target person description (vague vs. mixed) and prime valence (kinds vs. unkind). The participant's kindness judgment and overall impression of the target person were again the dependent measures.

\section{Procedure and materials}

After the participants entered the laboratory, they took place in individual cubicles and were told that they would participate in a sequence of unrelated tasks they had to complete individually. The sequence of tasks consisted of: (a) a reading task; (b) a word recognition task involving the subliminal priming procedure, (c) the judgment task and (d) a post-experimental questionnaire. Finally, participants were thanked for their participation and debriefed. 


\section{$\underline{\text { Reading task }}$}

The reading task was identical to the tasks used in study 1 . Participants were either asked to read the vague target person description consisting of six vague behavioral instances or to read the mixed target person description with three kind and three unkind behaviors.

\section{Priming manipulation}

After participants finished reading the target person description, they were presented with a word-recognition task. Participants performed this task on a computer. They were told they would see 14 letter strings appearing one by one on the computer screen. Half of these letter strings were existing words, the other half were non-existing words. Each trial started with the presentation of a fixation point on the computer screen. To start a trial the participants had to press the key ' 2 '. They had to decide as quickly as possible whether or not a string was an existing word by pressing a key on the keyboard (' 1 ' for existing word and ' 3 ' for a non-existing word). In order to get acquainted with this procedure, they started with four test trials.

After the test trials the participants proceeded to the 14 actual trials. During these trials, the strings were preceded by subliminal primes. These primes were words that were presented for $17 \mathrm{~ms}$ and masked by a row of X's ("XXXXXXXXXXXX") remaining on the screen for $225 \mathrm{~ms}$. The target word immediately followed this mask. All participants were exposed to 7 different prime words, each used twice. The prime words were traits retained from the pretest. In the kind prime valence condition these were: liked, goodhearted, sympathetic, kind, polite, helpful and pleasant. In the unkind valence condition these traits were: disliked, evil-hearted, unsympathetic, unkind, impolite, unhelpful and unpleasant $^{5}$. The participants were randomly assigned to one of the two prime valence conditions.

\footnotetext{
${ }^{5}$ In Dutch, the kind primes were: "geliefd", "goedaardig", "sympathiek", "aardig”, "beleefd", "behulpzaam" en "aangenaam". The unkind primes were: "ongeliefd", "kwaadaardig”, "onsympathiek", "onaardig", "onbeleefd", "onbehulpzaam" en "onaangenaam".
} 


\section{$\underline{\text { Judgment task }}$}

Like in study $1 \mathrm{~b}$, participants were asked to judge the target person with respect to 11 personality traits on a seven-point scale. The focal trait 'kind' was the second trait, after intelligence, the participants had to rate. When all traits were rated, the participants were also asked to indicate their overall impression of the target person $(1=$ extremely negative, 7 = extremely positive).

\section{Post-experimental questionnaire}

At the end of the experimental session, participants were asked to complete a form that probed for awareness and suspicion about any relatedness among tasks (see funneled debriefing procedure, Chartrand \& Bargh 1996). None of the participants could retrieve any of the primes or indicated any suspicion.

\section{Results}

A 2 (target person description: mixed vs. vague) x 2 (prime valence: kind vs. unkind) between-subjects ANOVA was conducted on the kindness judgment. As expected, we obtained a significant interaction between target person description and prime valence $(F(1,73)=8.85, p<.01)$. The means of this interaction are presented in figure 4. 
FIGURE 4

MEAN KINDNESS JUDGMENT AS A FUNCTION OF TARGET PERSON DESCRIPTION AND PRIME VALENCE (STUDY 2)

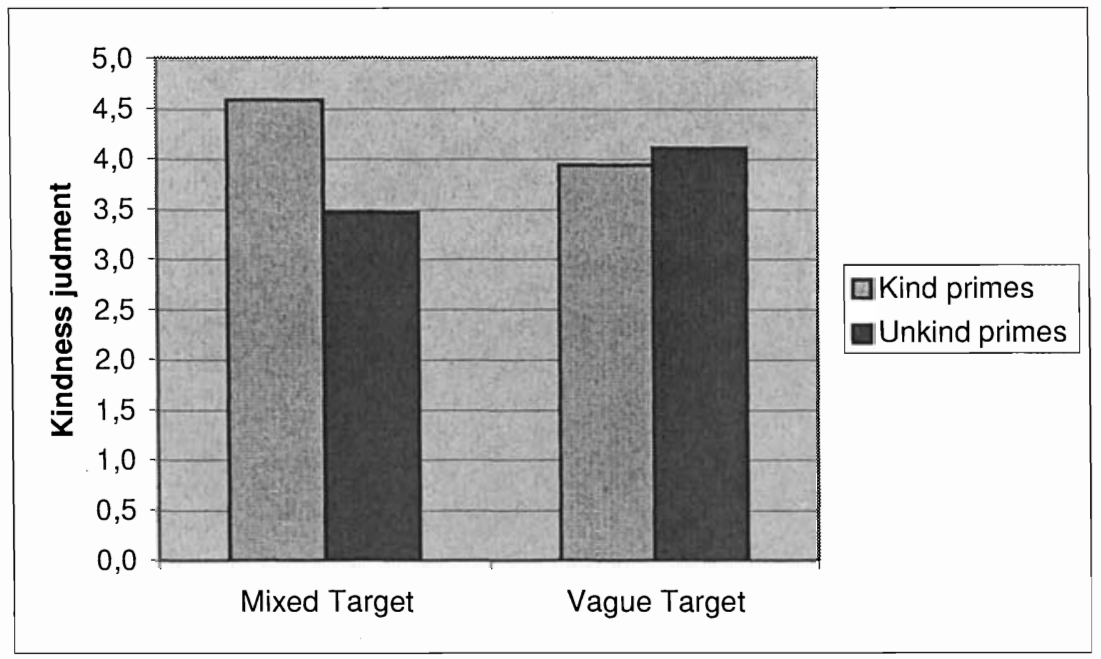

Contrasts between the kind and unkind prime valence revealed the expected significant difference for the mixed target person $(F(1,73)=13.67, p<.001)$. The participants judged the mixed target person as kinder in the kind valence condition $(M=$ 4.59) than in the unkind valence condition $(M=3.47)$. Also as predicted, we observed no difference for the vague target person $(M=3.94$ vs. $M=4.11)(F(1,73)=.27, p>.60)$. Next, the contrast between the mixed and vague target person description is significant for both the kind $(F(1,73)=4.79, p<.03)$ and the unkind primes $(F(1,73)=4.10, p<.04)$. These data show that the participants who received the kind primes perceived the mixed target person $(M=4.59)$ as kinder than the vague target person $(M=3.94)$. When receiving unkind primes, however, they rated the mixed target person $(M=3.47)$ as less kind than the vague one $(M=4.11)$. This indicates that compared to the vague target person condition, the primes result in kindness ratings that are congruent with their valence when the target person is mixed.

The same ANOVA was also computed on the overall judgment scores. As depicted in figure 5, the results show a significant interaction between target person description and prime valence $(F(1,73)=8.59, p<.01)$. 


\section{FIGURE 5}

MEAN OVERALL IMPRESSION JUDGMENT AS A FUNCTION OF TARGET PERSON DESCRIPTION AND PRIME VALENCE (STUDY 2)

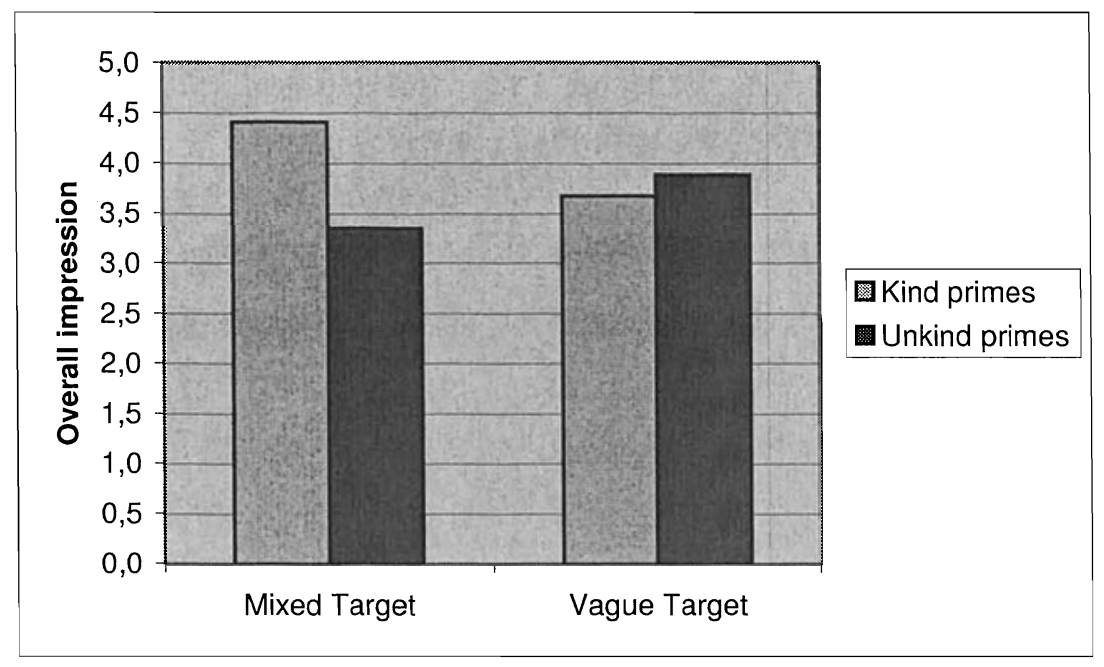

The data revealed a significant difference between the kind $(M=4.41)$ and unkind primes $(M=3.35)$ when the target person description was mixed $(F(1,73)=12.00, p<$ $.001)$. The difference between kind and unkind primes was not significant in the vague target person condition $(M=3.68$ vs. $M=3.89)(F(1,73)=.47, p>.49)$.

The data in this study perfectly matched our expectations. First, the assimilation effect of the mixed target person was much stronger compared to the assimilation effects obtained in study 1. This is in line with a number of other studies (e.g. Newman and Uleman 1990, Strack et al. 1993) suggesting that assimilation effects of priming are more likely when people are not aware of the priming event at the time they make their judgment (Higgins 1996). Also the main effect of target person description disappeared. Overall the mixed target person was perceived as kind as the vague target person. Finally, the perception of the vague target person was independent of the traits that were activated. 


\section{Study 3}

In the previous studies, our expectations were partially built on the assumption that people do not spontaneously establish actor-trait links when they encode behavioral instances. When people were then asked to judge the target person they were expected to base their judgment on the retrieval of applicable behaviors. If, however, people do make an actor-trait link at encoding and given that people tend to rely on a previous inference instead of the stored behavioral instances (Carlston 1980, Srull and Wyer 1980, Stapel et al. 1997), the trait concepts that are activated at the judgment stage are expected to have no effect on subsequent trait judgments. Ross et al. (1977) for instance found that once people constructed an explanation, they used this explanation instead of the original information on which it was based. Similarly, Ostrom et al. (1980) found that people made their person judgment on the basis of the impression formed at encoding, without reference to the original behavioral information. And finally, Carlston (1980) showed that, when asked to make a trait inference after encoding mixed target person behaviors, people based their final impression on this inference instead of on the actual behaviors.

Previous studies found that people make spontaneous trait inferences when encoding behavioral information about a person if they are motivated to do so. When people were given impression formation instructions at encoding, for instance, they were found to establish actor-trait links. When people, on the other hand, were given memorization instructions, these personality trait inferences were not observed (Uleman and Moskowitz 1994). By consequence, we expected that, when people have a memorization goal at encoding, activated traits would result in an assimilation effect. When people have a impression formation goal at encoding, however, we expected them to use this impression when judging. Consequently the activated traits were expected to have no effect on the target person judgment. 


\section{Method}

\section{Participants and Design}

Seventy-six undergraduates of Tilburg University participated in partial fulfillment of course requirements. The design of this study consisted of two between-subjects factors: instructions (memorization vs. impression) and prime valence (kind vs. unkind). Like in the previous studies, the dependent measure was the kindness judgment and overall attitude towards the target person.

\section{Procedure and materials}

After participants entered the laboratory, they were told that they would participate in a sequence of tasks and were then brought to individual cubicles. They were requested to perform a sequence of tasks: (a) a reading task; (b) a word recognition task involving the subliminal priming procedure; (c) the judgment task and (d) a post-experimental questionnaire. At the end of the session, participants were thanked for their participation and debriefed.

This procedure was very similar to study 2, except for the reading task. In this task, we provided all participants with the mixed target person description. Instead of manipulating the target person description, we manipulated the instructions that the participants received. After the target person was introduced as Diederik, a student in Tilburg, the participants were either given memorization instructions or impression formation instructions. The participants with the memorization instructions were asked to memorize the behavioral instances. The participants receiving the impression formation instructions were asked to form an impression of Diederik. All participants were subsequently asked to perform this task conscientiously as they would be asked questions about Diederik later on in the session. The participants were randomly assigned to one of the two conditions. The priming task, the judgment task and the post-experimental questionnaire were identical to that of study 2 . 


\section{Results}

We performed a 2 (instructions: memorization vs. vague) x 2 (prime valence: kind vs. unkind) between-subjects ANOVA on the kindness ratings. The data showed a marginally significant interaction between instructions and prime valence $(F(1,84)=$ $7.68), p<.06)$. The means pertaining to this interaction are presented in figure 6 .

\section{FIGURE 6}

MEAN KINDNESS JUDGMENT AS A FUNCTION OF INSTRUCTIONS AND PRIME VALENCE (STUDY 3)

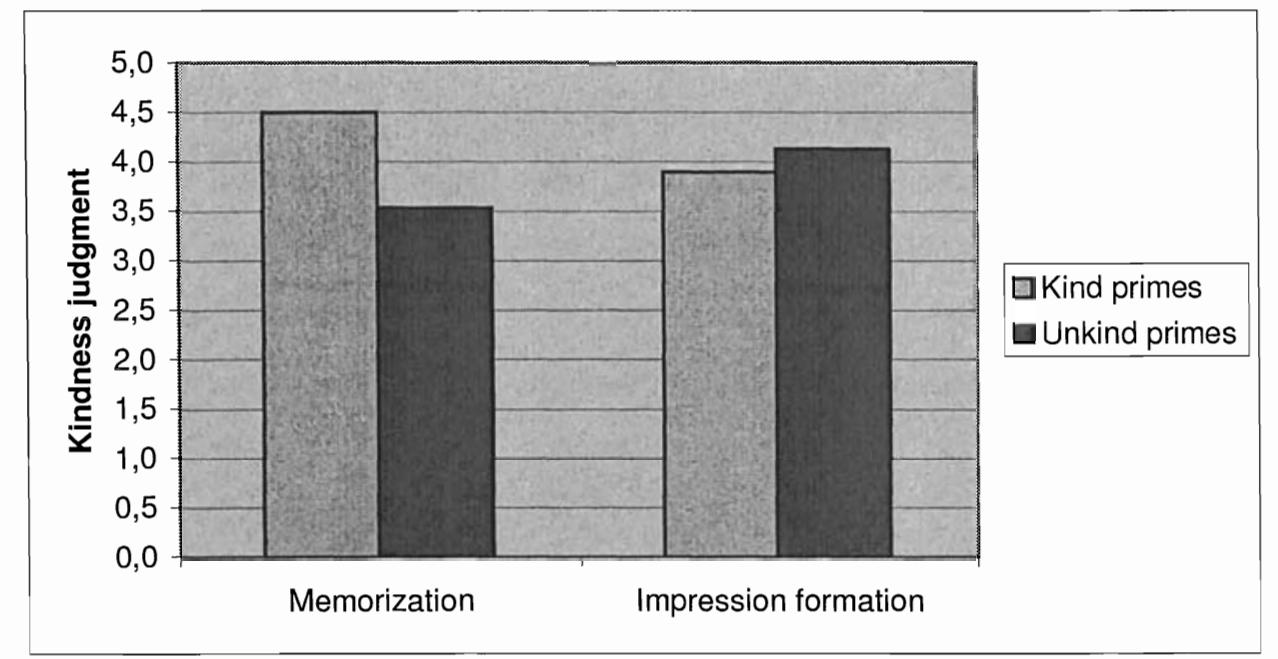

A planned comparison on the kindness measure revealed that there was a significant difference between the kind prime valence condition $(M=4.50)$ and unkind prime valence condition $(M=3.54)$ when participants were instructed to memorize the target person descriptions $(F(1,84)=10.02), p<.01)$. When participants were asked to form an impression of the target person, the primes had no differential effect ( $M=3.90$ vs. $M=4.13)(F(1,84)=.54), p>.46)$. The data also revealed that people, after receiving kind primes, perceived the target person as kinder in the memorization $(M=4.50)$ compared to the impression formation condition $(M=3.90)(F(1,84)=3.69, p<.06)$. When exposed to unkind primes, on the other hand, the participants in the memorization condition $(M=3.54)$ rated the target person as less kind than those in the impression formation condition $(M=4.13)(F(1,84)=3.69, p<.06)$. 
We also computed the same $2 \times 2$ between-subjects ANOVA on the overall impression ratings. Again, we observed a significant interaction between encoding instructions and prime valence $(F(1,84)=4.36, p<.04)$ The planned comparisons resulted in a marginally significant difference between the kind prime valence condition $(M=4.18)$ and unkind prime valence condition for the memorization instructions $(M=$ 3.41) $(F(1,84)=6.30), p<.02)$. No such difference emerged for the impression formation instructions $(M=3.72$ vs. $M=3.86)(F(1,84)=.20), p>.65)$.

As predicted, the post-primed traits resulted in an assimilation effect when people were asked to simply memorize the behavioral instances. This provides evidence for the fact that people with a memorization goal spontaneously refer traits to the behavioral instances and that subsequent priming with traits leads to selective use of congruent behaviors when judging. No effect of the activated traits was observed in the impression formation condition. When people are explicitly asked to form a target person impression at encoding, they very likely used this impression, and not the stored behaviors, during later judgment tasks.

\section{General conclusion}

It has been well accepted in the social cognition literature that activated trait knowledge only has an effect on the encoding of target person information that lacks evaluative clarity. More specifically, trait knowledge that is activated at the encoding stage has been shown to lead to either the disambiguation of ambiguous behavioral descriptions or the selective processing of mixed target person information (Stapel and Schwarz 1998), both resulting in an assimilation effect on subsequent target person judgments. Beyond the encoding stage, activated trait knowledge has been assumed to have no effect on target person judgments (e.g. interpretation/comparison model of Stapel et al. 1997). The current results however show that activated trait concepts can have a significant effect after the encoding stage. The present studies provide strong indications that subtle environmental cues lead to the selective use of previously stored prime-congruent behaviors, resulting in an assimilation effect on target person judgments. In other words, activated traits very likely make congruent behaviors more accessible at the judgment stage. In short, we 
propose an extension of the two-stage interpretation-at-encoding and comparison-atjudgment model to a three-stage model by adding a retrieval stage. This retrieval stage precedes the comparison stage. When people are asked to make a person judgment, they will try to retrieve the applicable previously made inference or, in absence of such stored inference, previously encoded behavioral information. Activated trait concepts might then bias this retrieval of behavioral instances.

Our findings also extend other studies that already indicated the selective use of prime-congruent episodes. Reyes, Thompson and Bower (1980), for instance, showed that evidence that was more accessible simply because it was more vivid, was better recalled and had a greater influence on juror verdicts. And Stapel and Schwarz (1998) similarly found that people when primed at encoding based their judgment of a mixed target person on prime congruent episodes. In both articles the authors attribute their findings to the differential attention paid to salient and prime congruent episodes, so that these episodes are preferentially perceived and processed. In our studies, however, the nature of the selective use is quite different. Knowledge categories are activated after the target person information is processed. By consequence, our findings are very likely due to differential retrieval instead of prime-congruent encoding. In this sense our findings correspond to those of Forgas and Moylan (1987) who showed that happy or sad movies influenced the departing moviegoers' answers with respect to a wide variety of topics: political judgments, expectations about the future, judgments of responsibility and quilt and quality of life judgments. The authors identify two possible explanations for their results. First, people might erroneously base their judgment on the activated mood. Next, it could also be that much of the judgment relevant information is ambiguous so that mood-congruent categories serve as interpretation frameworks. This second explanation seems unlikely though since disambiguation of information is typically found at encoding and not at retrieval. Our results, however, favor an alternative explanation: it is not unlikely that the topic information people possess is mixed and that the activated mood makes congruent facts more accessible.

Our results provide some evidence that the higher accessibility of stored primecongruent behaviors is indeed the underlying reason for the observed assimilation effect. When the target person was vague and no congruent behaviors were available, or when 
people were motivated to already form an impression at the encoding stage, the assimilation effect disappeared. However, these results provide only indirect support. The question therefore arises to what extent accessibility differences are indeed the underlying mechanism for the observed post-prime assimilation effects. Future research could try to obtain more confirming evidence by using a dependent measure more directly capturing accessibility differences, like a recall task. 


\section{References}

Bassili, J. N., (1989), "Trait Encoding in Behavioral Identification and Dispositional Inference," Personality and Social Psychology Bulletin, 15, 285-296.

Carlston, D. E., (1980), “The Recall and Use of Traits and Events in Social Inference Processes," Journal of Experimental Social Psychology, 16, 303-328.

Chatrand, T.L., and J.A. Barch (1996), "Automatic Activation of Impression Formation and Memorization Goals: Nonconscious Goal Priming Reproduces Effects of Explicit Task Instructions," Journal of Personality and Social Psychology, 71, 464-478.

Claeys, W., (1990), "On the Spontaneity of Behavior Categorization and its Implications for Personality Measurement," European Journal of Personality, 4, 173-186.

Eiser, J. R., (1990), Social Judgment, Milton Keynes, UK: Open University.

Forgas, J. P., and S. Moylan (1987), “After the Movies: Transient Mood and Social Judgments," Personality and Social Psychology Bulletin, 13, 467-477.

Herr, P. M., (1986), “Consequences of Priming: Judgment and Behavior,” Journal of Personality and Social Psychology, 51 (6), 1106-1115.

Herr, P. M., S. J. Sherman and R. H. Fazio (1983), “On the Consequences of Priming: Assimilation and Contrast Effects," Journal of Experimental Social Psychology, $19,323-340$.

Higgins, E. T., (1996), “Knowledge Activation: Accessibility, Applicability, and Salience," in Social Psychology: Handbook of Basic Principles, eds. E. T. Higgins and A. W. Kruglanski, New York, NY: Guilford, 133-168. 
Higgins, E. T., and C. M. Brendl (1995), “Accessibility and Applicability: Some 'Activation Rules' Influencing Judgment," Journal of Experimental Social Psychology, 31, 218-243.

Higgins, E. T., W. S. Rholes and C. R. Jones (1977), “Category Accessibility and Impression Formation," Journal of Experimental Social Psychology, 13, 141-154.

Newman, L. S., and J. S. Uleman (1990), "Assimilation and Contrast Effects in Spontaneous Trait Inference," Personality and Social Psychology Bulletin, 16, 224-240.

Ostrom, T. M., J. H. Lingle, J. B. Pryor and N. Geva (1980), “Cognitive Organization of Person Impressions," in Person Memory: The Cognitive Basis of Social Perception, eds. R. Hastie et al., Hillsdale, NJ: Erlbaum.

Reyes, R. M., W. C. Thompson and G. H. Bower (1980), “Judgmental Biases Resulting From Differing Availabilities of Arguments," Journal of Personality and Social Psychology, 39, 2-12.

Ross, L., M.R. Lepper, F. Strack and J. Steinmetz (1977), "Social Explanation and Social Expectation: Effects of Real and Hypothetical Explanations on Subjective Likelihood," Journal of Personality and Social Psychology, 32, 880-892.

Skowronski, J. J., D. E. Carlston and J. T. Isham (1993), “Implicit Versus Explicit Impression Formation: The Differing Effect of Overt Labeling and Covert Priming on Memory and Impressions," Journal of Experimental Social Psychology, 29, 1741.

Srull, T. K., (1983), "Organizational and Retrieval Processes in Person Memory: An Examination of Processing Objectives, Presentation Format and the Possible Role of Self-Generated Retrieval Cues," Journal of Personality and Social Psychology, 44, 1157-1170. 
Srull, T. K., and R. S. Wyer, Jr. (1979), "The Role of Category Accessibility in the Interpretation of Information About Persons: Some Determinants and Implications," Journal of Personality and Social Psychology, 37 (10), 1660-1672.

Srull, T. K., and R. S. Wyer, Jr. (1980), "Category Accessibility and Social Perception: Implications for the Study of Person Memory and Interpersonal Judgments," Journal of Personality and Social Psychology, 38 (6), 841-856.

Stapel, D. A., and W. Koomen (2001), "Let's not forget the past when we go to the future: On our knowledge of knowledge accessibility effects," in Cognitive social psychology: The Princeton symposium on the legacy and future of social cognition, ed. G Moskowitz, Mahwah, NJ: Lawrence Erlbaum, 229-246.

Stapel, D. A., W. Koomen and J. van der Pligt (1996), “The Referents of Trait Inferences: the Impact of Trait Concepts Verus Actor-Trait Links on Subsequent Judgments," Journal of Personality and Social Psychology, 70 (3), 437-450.

Stapel, D. A., W. Koomen and J. van der Pligt (1997), "Categories of Category Accessibility: The Impact of Trait Concept versus Exemplar Priming on Person Judgments," Journal of Experimental Social Psychology, 33, 47-76.

Stapel, D. A., and N. Schwarz (1998), "Similarities and Differences between the Impact of Traits and Expectancies: What Matters Is Whether the Target Stimulus Is Ambiguous or Mixed," Journal of Experimental Social Psychology, 34, 227-245.

Strack, F., N. Schwarz, H. Bless, A. Kubler and M. Wanke (1993), "Awareness of the Influence as a Determinant of Assimilation Versus Contrast," European Journal of Social Psychology, 23, 53-62.

Tversky, A., and D. Kahneman (1973), “Availability: A Heuristic for Judging Frequency and Probability," Cognitive Psychology, 5, 207-232. 
Tversky, A., and D. Kahneman (1974), “Judgment under Uncertainty: Heuristics and Biases," Science, 185, 1124-1131.

Uleman, J. S., L. S. Newman and G. B. Moskowitz (1996), "People as Flexible Interpreters: Evidence and Issues from Spontaneous Trait Inferences," Advances in Experimental Social Psychology, 28, 211-279.

Uleman, J. S., and G. B. Moskowitz (1994), Unintended Effects of Goals on Unintended Inferences," Journal of Personality and Social Psychology, 66, 490-501.

Uleman, J. S., G. B. Moskowitz, R.J. Roman and E. Rhee (1993), "Tacit, Manifest, and Intentional Reference: How Spontaneous Trait Inferences Refer to Persons," Social Cognition, 11, 321-351.

Winter, L., and J. S. Uleman, (1984), "When Are Social Judgments Made? Evidence For the Spontaneous Activation of Trait Inferences," Journal of Personality and Social Psychology, 47, 237-252. Also see correction in Journal of Personality and Social Psychology (1986), 50, 355.

Wyer, R. S. Jr., and T. K. Srull (1989), Memory and Cognition in its Social Context, Hillsdale, NJ: Lawrence Erlbaum. 

